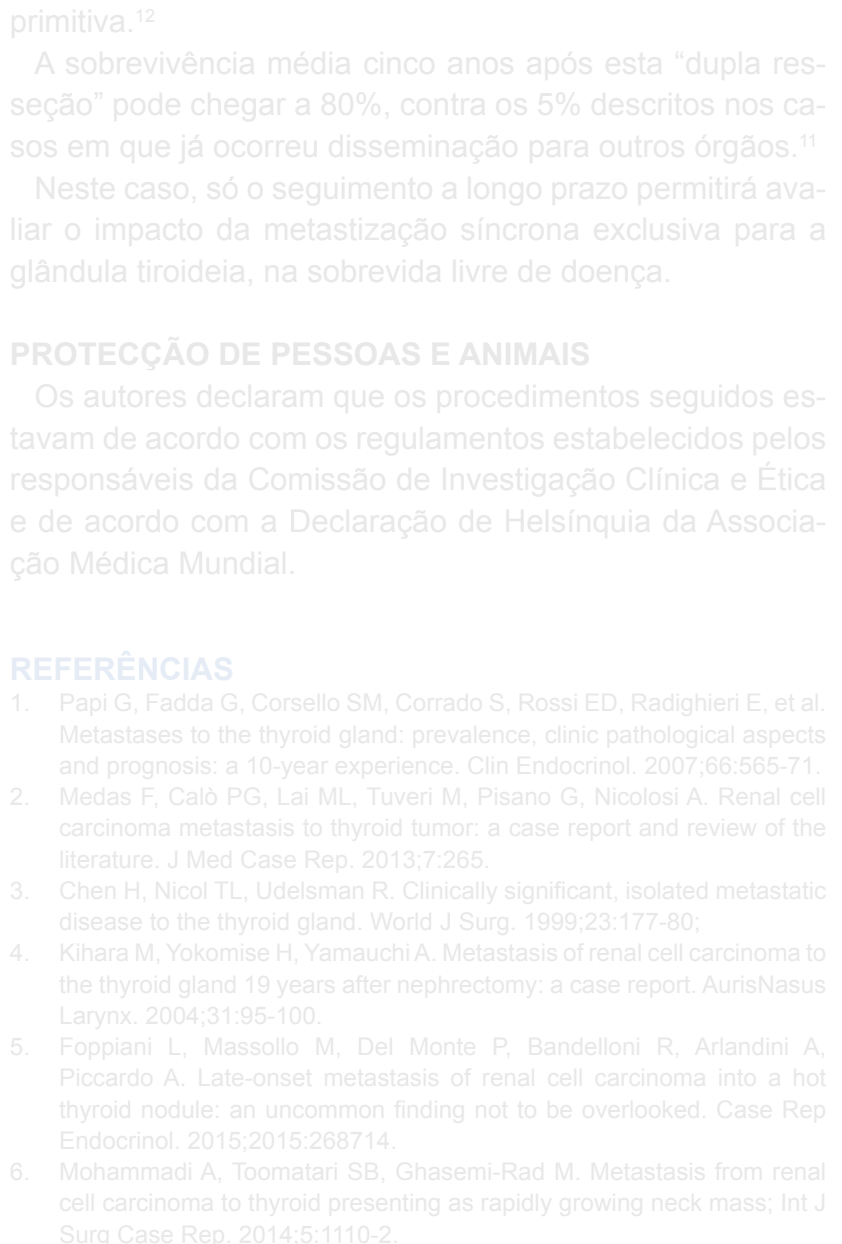

CONFLITOS DE INTERESSE

\title{
Flagrante de uma Fratura da Clavícula por Acidente Tauromáquico
}

\section{Flagrant of a Clavicle Fracture as Bullfight Injury}

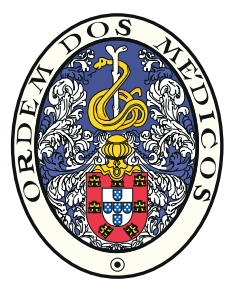

Carlos DURÃOه1, Jorge RAMOS 1

Acta Med Port 2016 Nov;29(11):758-760 - http://dx.doi.org/10.20344/amp.8320

\section{RESUMO}

O Hospital de Vila Franca de Xira está localizado na região com maior número de festejos e atividades tauromáquicas de Portugal. Como consequência natural, o hospital acaba por possuir uma particular experiência no tratamento de vítimas de acidentes tauromáquicos. São normalmente populares colhidos em festejos de rua oriundos das festas tradicionais da região, mas também os acidentes de trabalho de profissionais como campinos, maiorais, ganadeiros entre outros que manejam o gado bravo com destaque para os profissionais do toureio, forcados, bandarilheiros, matadores e cavaleiros. Embora possamos remeter-nos para as lesões perfurantes geradas pelos cornos dos touros, são as lesões de natureza contundente as mais frequentes, entre elas as contusões e fraturas dos membros. Este trabalho mostra o flagrante de uma típica cornada, demonstrando a violência do traumatismo nos acidentes tauromáquicos, que neste caso resultou apenas na fratura da clavícula do membro atingido na queda.

Palavras-chave: Clavícula/lesões; Fraturas Ósseas; Gado; Traumatismos em Atletas.

\section{ABSTRACT}

The Vila Franca de Xira Hospital is located in the region with the highest number of festivals and bullfighting activities of Portugal. As a natural consequence, the hospital ends up with a particular experience in the treatment of victims of bullfighting accidents. These are usually common people harvested in street celebrations during the traditional festivals of the region, but also workers such as cattle herders, foremen, ranchers and others who handle the wild cattle and in particular those who deal with the bulls, such as forcados, banderilleros, matadors and cavaleiros. Although we may refer the perforating injuries generated by the horns of bulls, the most

1. Serviço de Ortopedia. Hospital de Vila Franca de Xira. Vila Franca de Xira. Portugal.

$\triangle$ Autor correspondente: Carlos Durão. drcarlosdurao@hotmail.com

Recebido: 16 de outubro de 2016 - Aceite: 21 de outubro de 2016 | Copyright $\odot$ Ordem dos Médicos 2016 
frequent injuries are the blunt ones, among them bruises and fractures of the limbs. This work shows the typical striking of a bull horn, showing the violence of the trauma in bulfighting accidents, which in this case resulted only on the fracture of the clavicle from the member hit in the fall.

Keywords: Athletic Injuries; Cattle; Clavicle/injuries; Fractures, Bone.

O Hospital de Vila Franca de Xira está localizado na região com maior número de festejos e atividades tauromáquicas de Portugal. Como consequência natural, o hospital acaba por possuir uma particular experiência no tratamento de vítimas dos acidentes tauromáquicos. São normalmente populares colhidos em festejos de rua oriundos das festas tradicionais da região, mas também os acidentes de trabalho de profissionais como campinos, maiorais, ganadeiros entre outros que manejam o gado bravo com destaque para os profissionais do toreio, forcados, bandarilheiros, matadores e cavaleiros, ${ }^{1}$ Embora possamos remeter- nos para as lesões perfurantes geradas pelos cornos dos touros, são as lesões de natureza contundente as mais frequentes, dentre elas as contusões e fraturas dos membros.

A biomecânica do trauma é fundamental para a melhor abordagem e tratamento da vítima. Em cirurgia taurina é de grande importância o conhecimento do binómio touro versus vítima bem como o local onde acontece o acidente. As lesões podem variar consoante o animal envolvido bem como a ausência ou o uso de proteções nos cornos do animal dependendo do evento tauromáquico realizado. ${ }^{2,3}$

\section{RELATO DE CASO}

Homem de 69 anos, colhido por um touro, sofrendo um traumatismo na região glútea direita seguida por uma queda. A violência do traumatismo foi flagrada pelo registo fotográfico que demonstra a impressionante cinética do evento (Fig.1). A vítima, com a energia do trauma gerado pela cornada na região glútea direita, é projetada para cima e girando para a esquerda acaba por embater ao solo com o membro superior esquerdo, resultando na fratura diafisária da clavícula.

A vítima foi observada pela cirurgia geral e transferida posteriormente para a ortopedia, por apresentar exclusivamente a fratura da clavícula. Foi realizado o tratamento com a imobilização tipo cruzado posterior por cinco sema- nas, com a consolidação óssea da fratura e excelente recuperação funcional do doente, que voltou a participar de outras festas tauromáquicas (Fig.2).

\section{DISCUSSÃO}

As fraturas da clavícula são fraturas comuns, em regra causadas por quedas sobre o membro superior estendido. O mecanismo de ação mais comum é o impacto direto no ombro, forçando o terço lateral da clavícula em direção posterior e criando uma fratura do terço médio sobre o fulcro da primeira costela. ${ }^{4} \mathrm{~A}$ artéria e a veia subclávias, juntamente com o plexo braquial, passam imediatamente atrás da clavícula e estão vulneráveis durante o traumatismo bem como durante a osteossíntese, incluindo lesões pleuro pulmonares, como o pneumotórax. ${ }^{5}$

A maioria das fraturas claviculares é tratada sem cirurgias, mas existem indicações cirúrgicas, como as fraturas expostas, fraturas do terço distal, fraturas associadas as fraturas da omoplata (ombro flutuante) e as pseudartroses. Apesar de existirem cavilhas para osteossíntese clavicular, a fixação com placas e parafusos é o método de escolha para a maioria dos tratamentos cirúrgicos, permitindo técnicas de estabilidade relativa ou absoluta. ${ }^{6,7}$

Em todas as faixas etárias, as fraturas do terço médio da clavícula, na maioria dos casos, consolidam apenas com o tratamento conservador com imobilização tipo Gerdy ou cruzado posterior em forma de '8', que são muito eficazes no alívio da dor.

As taxas de não consolidação variam, mas em geral, são inferiores a $5 \%$, contudo é importante salientar que nem todas as não consolidações são sintomáticas, o que pesa mais ainda para a indicação do tratamento conservador. No entanto existem indicações relativas ao tratamento cirúrgico, entre elas as fraturas em doentes politraumatizados e fraturas bilaterais.

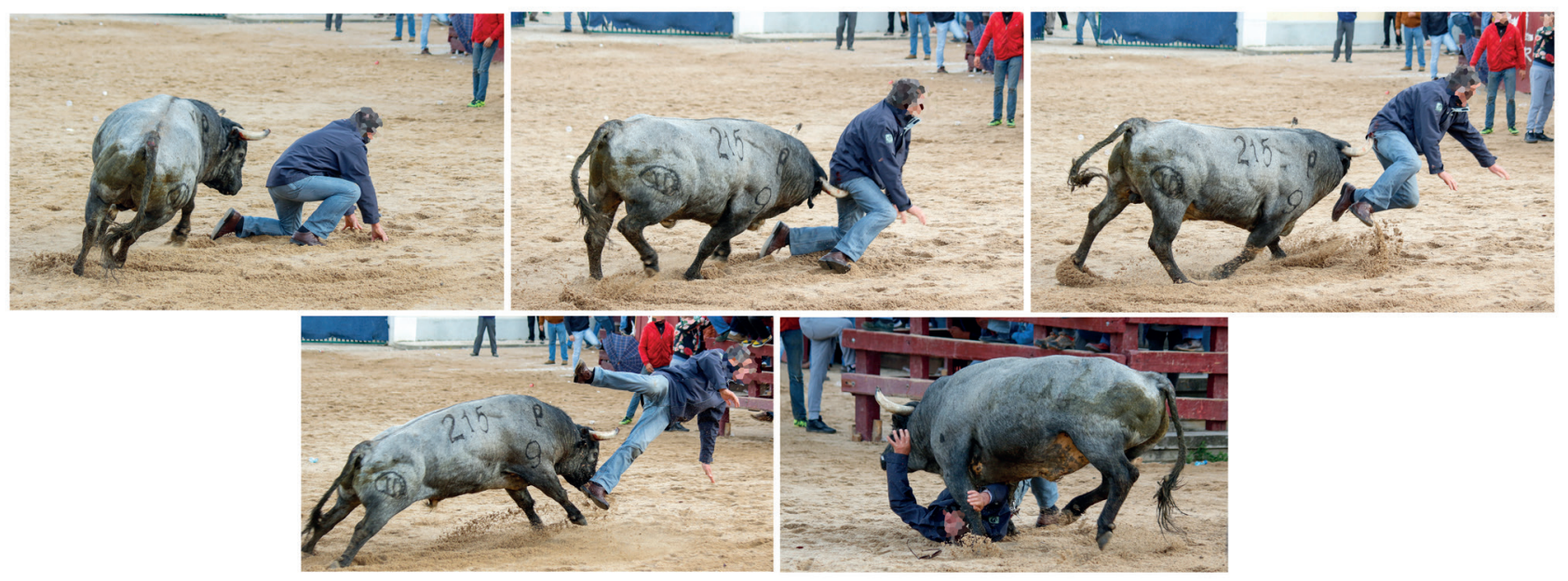

Figura 1 - Flagrante do acidente tauromáquico e a queda com traumatismo do membro superior esquerdo 

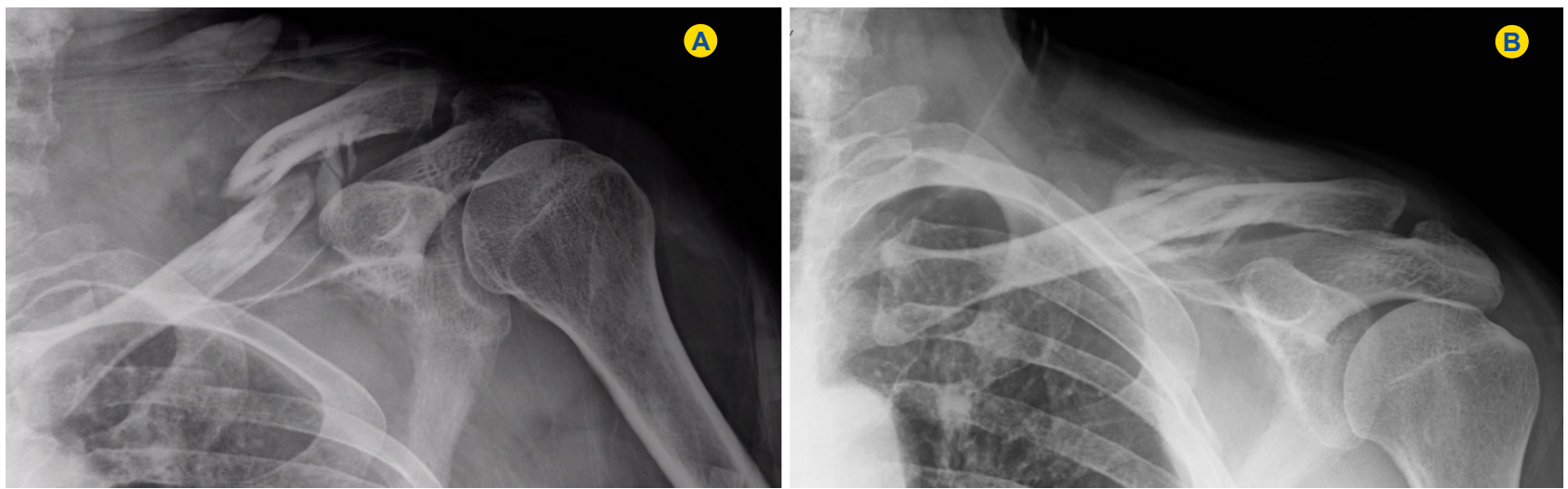

Figura 2 - Radiografia inicial evidenciando a fratura diafisária da clavícula esquerda e a mesma fratura consolidada após radiografia de controle com dez semanas, notar a presença do exuberante calo ósseo

\section{CONCLUSÃO}

Alguns estudos têm apresentado resultados superiores nos tratamentos cirúrgicos, ${ }^{7,8}$ mas estas indicações não são consensuais e a indicação cirúrgica nestas fraturas ainda é controversa. $\mathrm{O}$ tratamento cirúrgico também possui complicações, desde a pseudartrose, complicações vasculares intraoperatórias até problemas inerentes á cicatrização da ferida operatória. ${ }^{6,7}$

O presente caso é um bom exemplo de como fraturas diafisárias da clavícula podem ser tratadas de forma não cirúrgica. A consolidação óssea foi adequada e a recuperação funcional do doente foi muito satisfatória.

Fraturas da clavícula são frequentes nos acidentes tauromáquicos, não podendo esquecer que quando associadas às feridas ou fraturas expostas, estas são em regra, feridas que devem ser consideradas contaminadas, não só pelo animal vulnerante, mas também pelo local em que são produzidas, merecendo a cobertura antibiótica e profilaxia antitetânica mais adequada. ${ }^{3}$

\section{CONFLITOS DE INTERESSE}

Os autores declaram não terem qualquer conflito de interesse relativamente ao presente artigo.

\section{FONTES DE FINANCIAMENTO}

Os autores declaram não ter recebido subsídios ou bolsas para a elaboração do artigo.

\section{AGRADECIMENTOS} Amaro.

Fotografias da colhida gentilmente cedidas por Nuno

by an isolated midshaft clavicle fracture. Case Rep Emerg Med. 2016;2016:2409894.

6. Burnham JM, Kim DC, Kamineni S. Midshaft clavicle fractures: a critical review. Orthopedics. 2 016;39:e814-21.

7. Hanselman AE, Murphy TR, Bal GK, McDonough EB. Operative cost comparison: plating versus intramedullary fixation for clavicle fractures. Orthopedics. 2016;39:e877-82.

8. Brin YS, Palmanovich E, Dolev E, Nyska M, Kish BJ. Displaced midshaft clavicular fractures: is conservative treatment still preferred? Isr Med Assoc J. 2014;16:748-52. 